\title{
OTR14 - EXPERIÊNCIA DA DIVISÃO DE ATENDIMENTO AO CLIENTE E PÓS-MARKETING NO RELACIONAMENTO COM EMPRESAS PRESTADORAS DE SERVIÇOS
}

Linda Khalili Boukai, Caroline Ferezin Pinto, Flávia Fontenelle Muylaert, Vanessa Martins da Silva, Ludmila Nascimento Rocha Villar Bezerra, Marilúcia Sobrado Pina, Priscila Caroline Almeida dos Santos.

Divisão de Atendimento ao Cliente e Pós- Marketing, Departamento de Relações com o Mercado, Instituto de Tecnologia em Imunobiológicos, Fundação Oswaldo Cruz.

Objetivo: Este trabalho visa compartilhar a experiência da Divisão de Atendimento ao Cliente e Pós- Marketing, DIACM, no que se refere ao relacionamento entre BioManguinhos e as empresas parceiras contratadas que prestam serviços de assistência técnica à plataforma de equipamentos do kit NAT HIV/HCV em diversos níveis de atendimento.

Metodologia: A DIACM participou ativamente das diversas etapas da construção da relação contratual entre Bio-Manguinhos e três empresas privadas de caráter nacional/internacional fornecedoras dos equipamentos da plataforma NAT HIV/HCV. Sua atuação foi importante no alinhamento dos requisitos de atendimento de acordo com as demandas da Coordenação Geral de Sangue e Hemoderivados/ Ministério da Saúde. Uma vez estabelecidos os critérios, a DIACM teve uma postura determinada na elaboração, discussão e negociação das cláusulas contratuais e contou, também, com o apoio da gerência do Departamento de Relações com o Mercado, do Laboratório de Tecnologia Diagnóstica e do Núcleo de Assessoria Processual- que forneceu as diretrizes legais contempladas na Lei 8.666/93, subsidiando o diálogo entre as partes. Para atender aos requisitos da IN02, que na época regeu as orientações do Ministério do Planejamento, Orçamento e Gestão (MPOG) para contratos de terceirização de serviços, a DIACM elaborou os documentos necessários para esta modalidade contratação: Projeto Básico, Plano de Trabalho, Justificativa e Planilha de Custos da execução dos serviços. A DIACM trabalhou na construção dos requisitos para o desenvolvimento e implantação de um Sistema Operacional CRM (Customer Relationship Management) para gerenciar o relacionamento entre Bio-Manguinhos, empresas parceiras e os usuários no campo, 
tornando possível rastrear, acompanhar e compartilhar a resolução das ocorrências com fidelidade, em tempo real.

Resultado: O processo tramitou na Procuradoria/FIOCRUZ e, em dezembro de 2010, os contratos foram firmados com vigência de 60 meses. Houve uma intencional padronização entre as contratações de forma a harmonizar a regência e a fiscalização do contrato pelo servidor nomeado. Foram estabelecidos fluxos de comunicação interna e externa de forma a cumprir com os requisitos estabelecidos. Internamente, os fluxos foram desenhados para as diversas áreas envolvidas no processo de atendimento ao produto. Externamente, Bio-Manguinhos configurou-se como nível 1 de atendimento, sendo o primeiro canal de comunicação com os usuários. As empresas contratadas configuraram-se como nível 2. Os dados estatísticos da relação com as empresas parceiras revelam que, em 2012, foram registradas 1738 ocorrências e, destas, 61\% foram resolvidas por Bio-Manguinhos e 39\% resolvidas pelas empresas contratadas. Importante ressaltar que $77 \%$ das ocorrências foram resolvidas dentro do prazo estabelecido no POP da Divisão (DI 1232) que é de 20 horas comerciais em todo o Brasil.

Conclusão: A relação entre Bio-Manguinhos e as parceiras contratadas se estabeleceu de forma consensual e estruturada, com interação permanente, contribuindo para o sucesso da relação. As ocorrências foram resolvidas satisfatoriamente, em tempo oportuno, e continuamos buscando a melhoria contínua na prestação dos nossos serviços. 